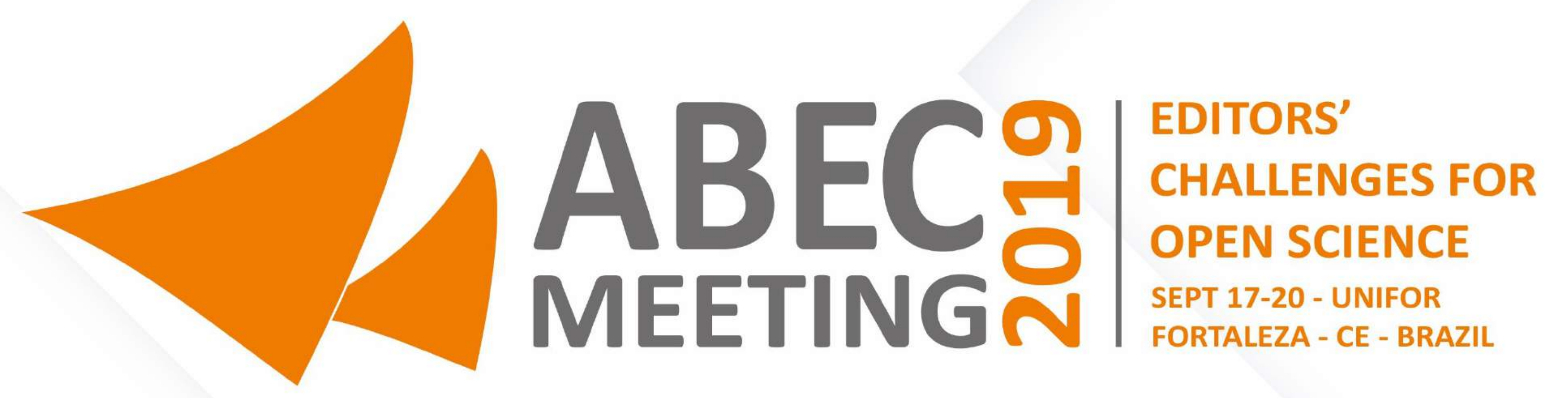

\title{
A trilha de um periódico científico de uma instituição particular na transição da publicação impressa à eletrônica e na busca de indexações internacionais
}

Márcia Thelma Rios Donato Marino. Juliana Maria de Sousa Pinto. Emanuela Paula Martins

\section{INTRODUÇÃO}

2014 - Impresso para Eletrônico

Contexto - SEER / OJS do cadastro/submissão à publicação

Plataforma Sucupira (Capes) - periódicos impressos e digitais surgiram ou foram descontinuados entre 2013 e 2014 / variabilidade na área tecnológica

Profissionais / Periódicos Científicos - quebra da endogenia / requisito indexadores internacionais

\section{OBJETIVO}

Relatar os desafios de um periódico científico na transição da publicação impressa à eletrônica e a quebra da endogenia acadêmica, buscando adequações aos indexadores internacionais.

\section{METODOLOGIA}

$\begin{array}{ll}\text { Natureza } & \text { Descritivo - exploratório } \\ \text { Método } \longrightarrow & \text { Estudo de caso } \\ \text { Abordagem } \longrightarrow & \text { Quantitativa } \\ \text { Pesquisa bibliográfica } \longrightarrow \text { Bases de dados digitais } \\ \text { Pesquisa documental } \longrightarrow \text { Análise de documentos } \\ \text { Amostra } \longrightarrow \begin{array}{l}\text { Trabalhos publicados entre } 2009 \text { e } 2019 \\ \text { Revista Tecnologia - Unifor }\end{array}\end{array}$

\section{O CASO DA REVISTA TECNOLOGIA}

Q 2 Lançamento

1980.

$\Upsilon_{2012 \text { - Gestão atual }}$

Fortalecimento da revista junto às comunidades acadêmicas nacionais e internacionais.

\section{Periodicidade Semestral.}

\section{Adversidades} Mudanças de editores; Apoio logístico; Descontinuidade da periodicidade; Endogenia; Migração tardia para o formato eletrônico. $\uparrow_{\text {Missão }}$

Divulgar o conhecimento tecnológico e científico nas áreas da tecnologia.

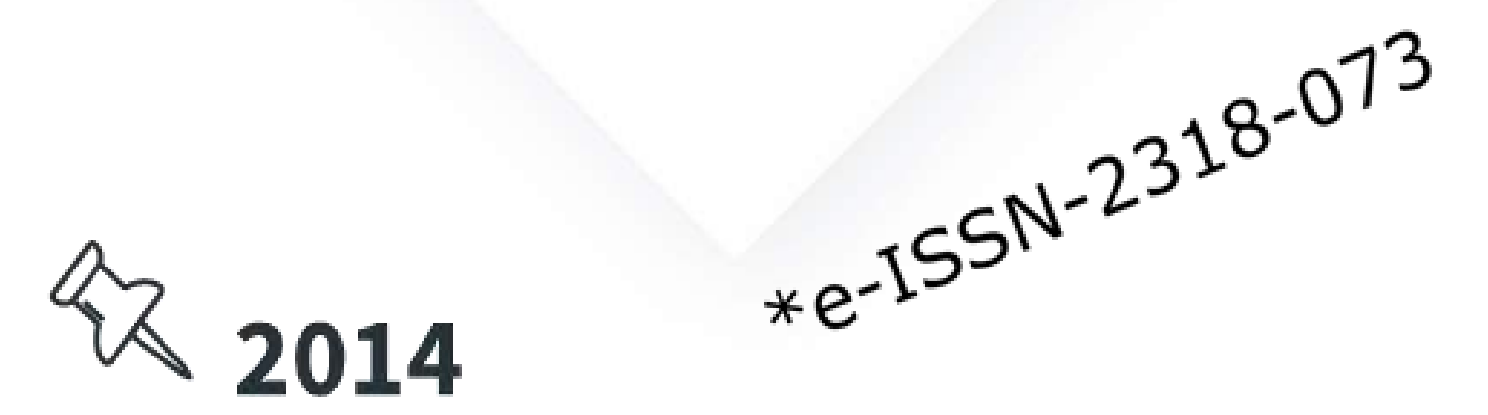

Início da transição da editoração impressa para a eletrônica; Portal de Periódicos Unifor (SEER/OJS).

Plataforma Sucupira Qualis B5 (2014)

Áreas de Engenharias II, Engenharias III e Interdisciplinar.

\section{Avaliação}

2 etapas sequenciais: quanto à formatação $e$ ineditismo e double blind review.
Turnitin

Verificação de existência de similaridade em todos os manuscritos submetidos.

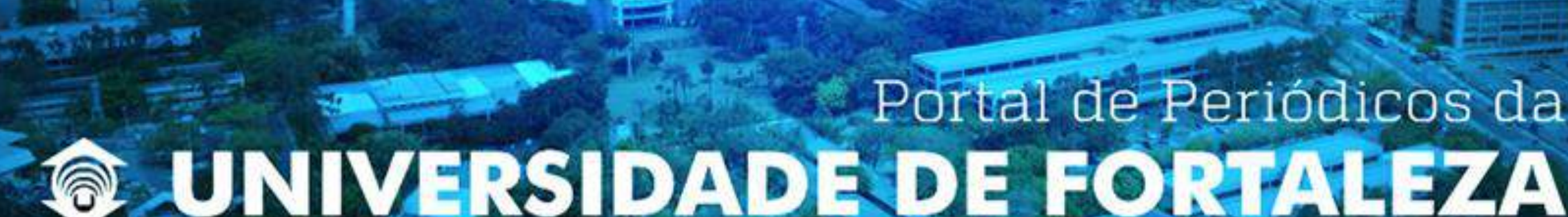

https://periodicos.unifor.br/
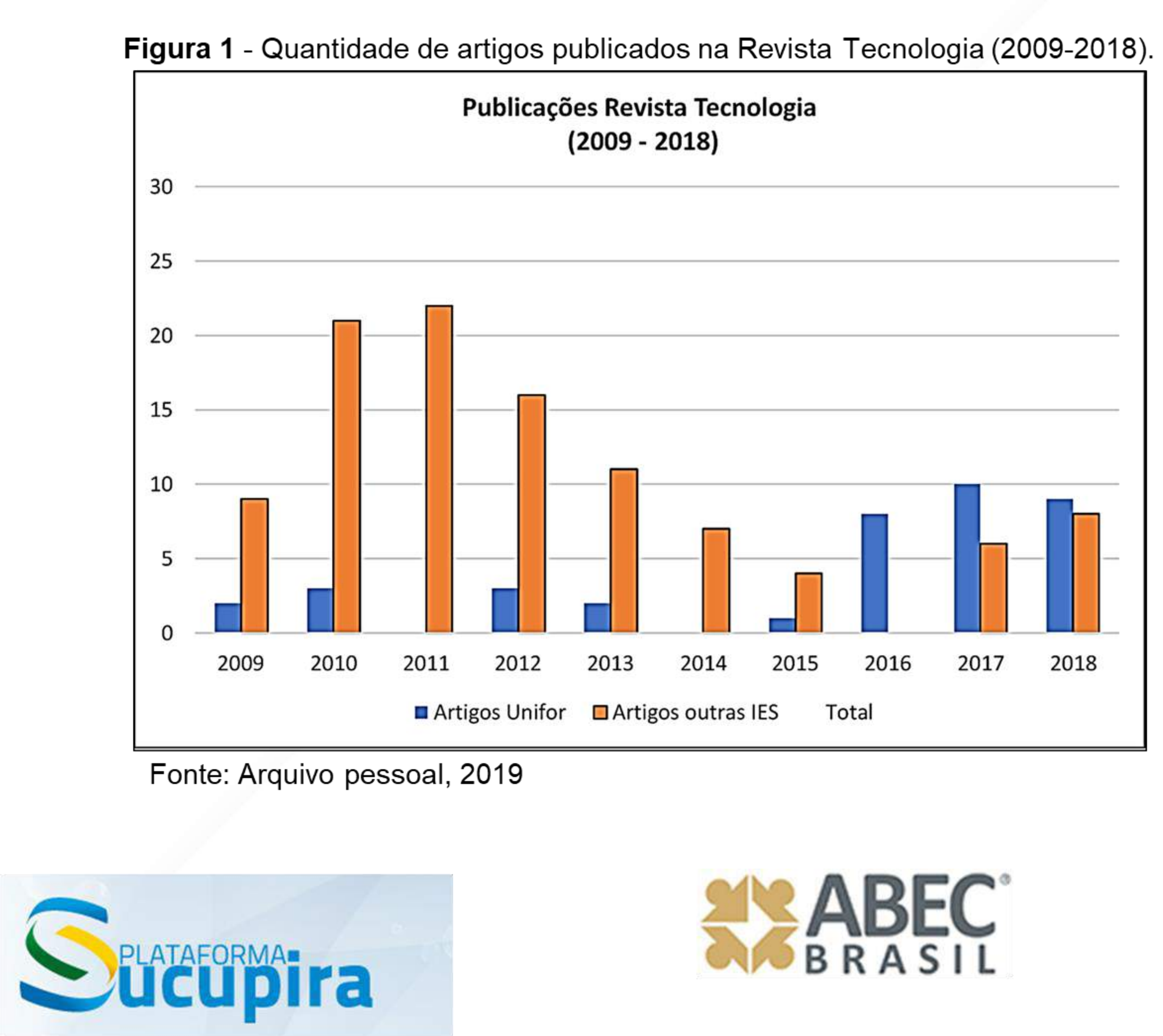

的

Qualis Referência B3 CAPES (2019)

Fator positivo para abertura de novas oportunidades

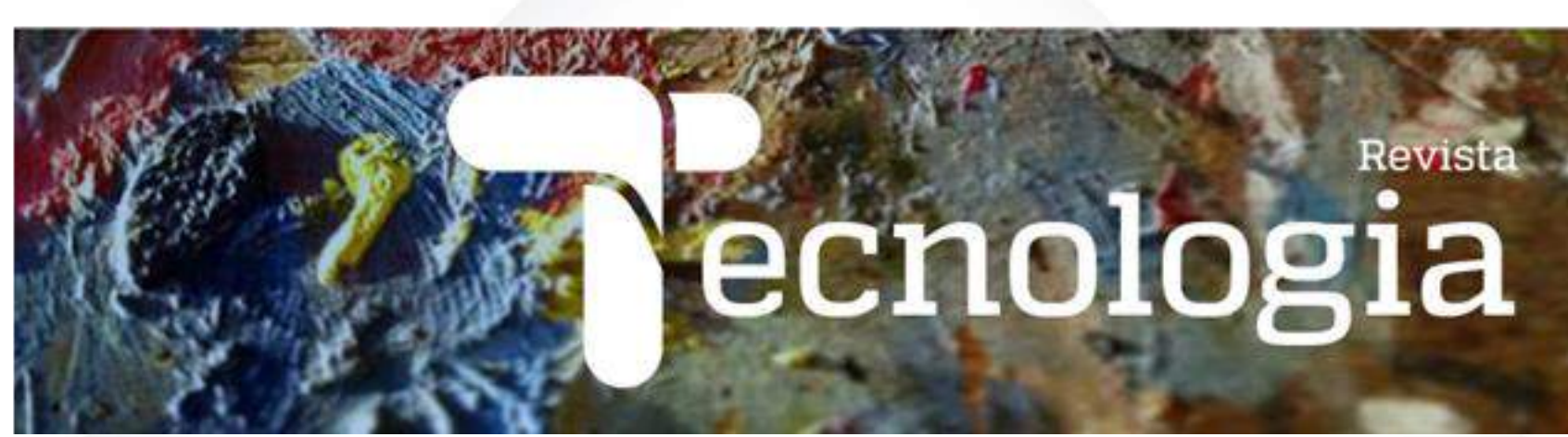

DESAFIOS
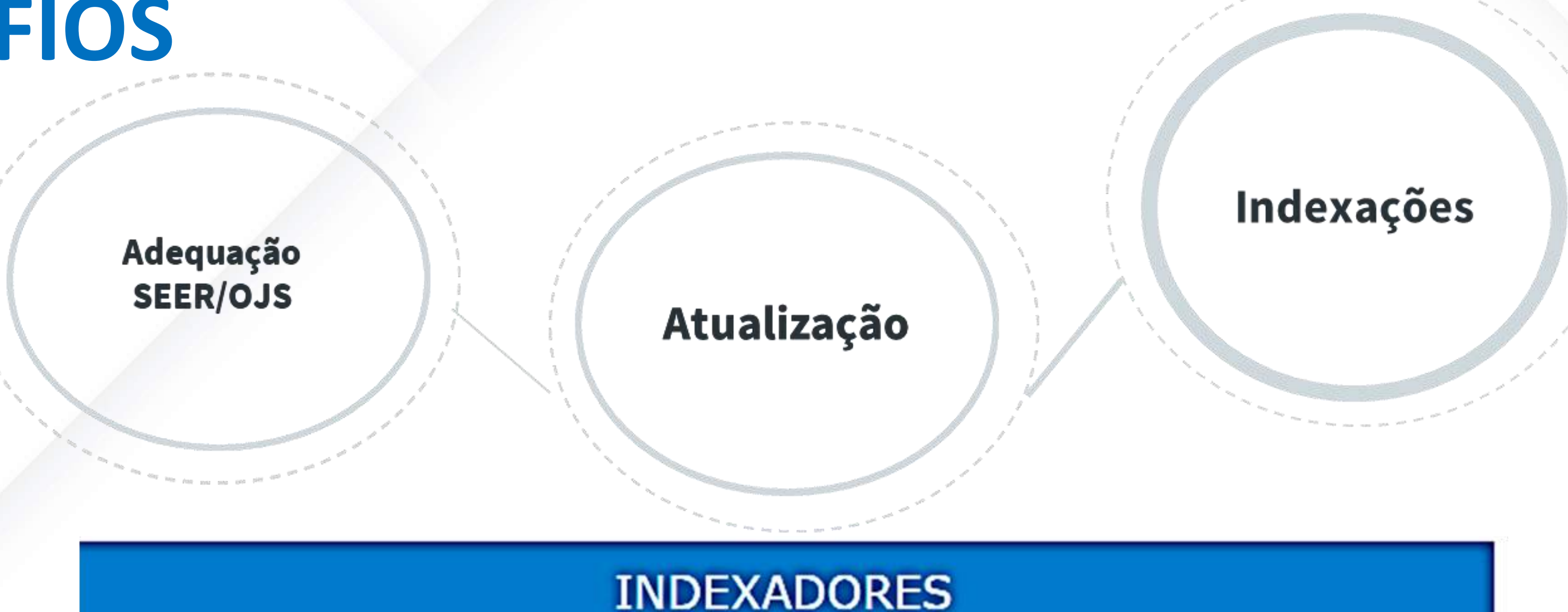

DOA

INDEXADORES

: CiteFactor

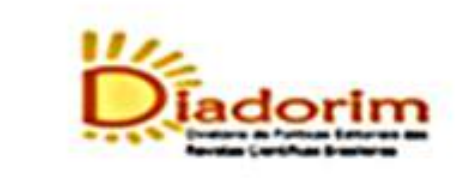

Crossret

Google

\section{CONCLUSÃO}

Sistema Eletrônico de Editoração de Revistas (SEER) do Open Journal Systems (OJS)

Internacionalização

\section{Networking}

Desafios, planejamento e ações.

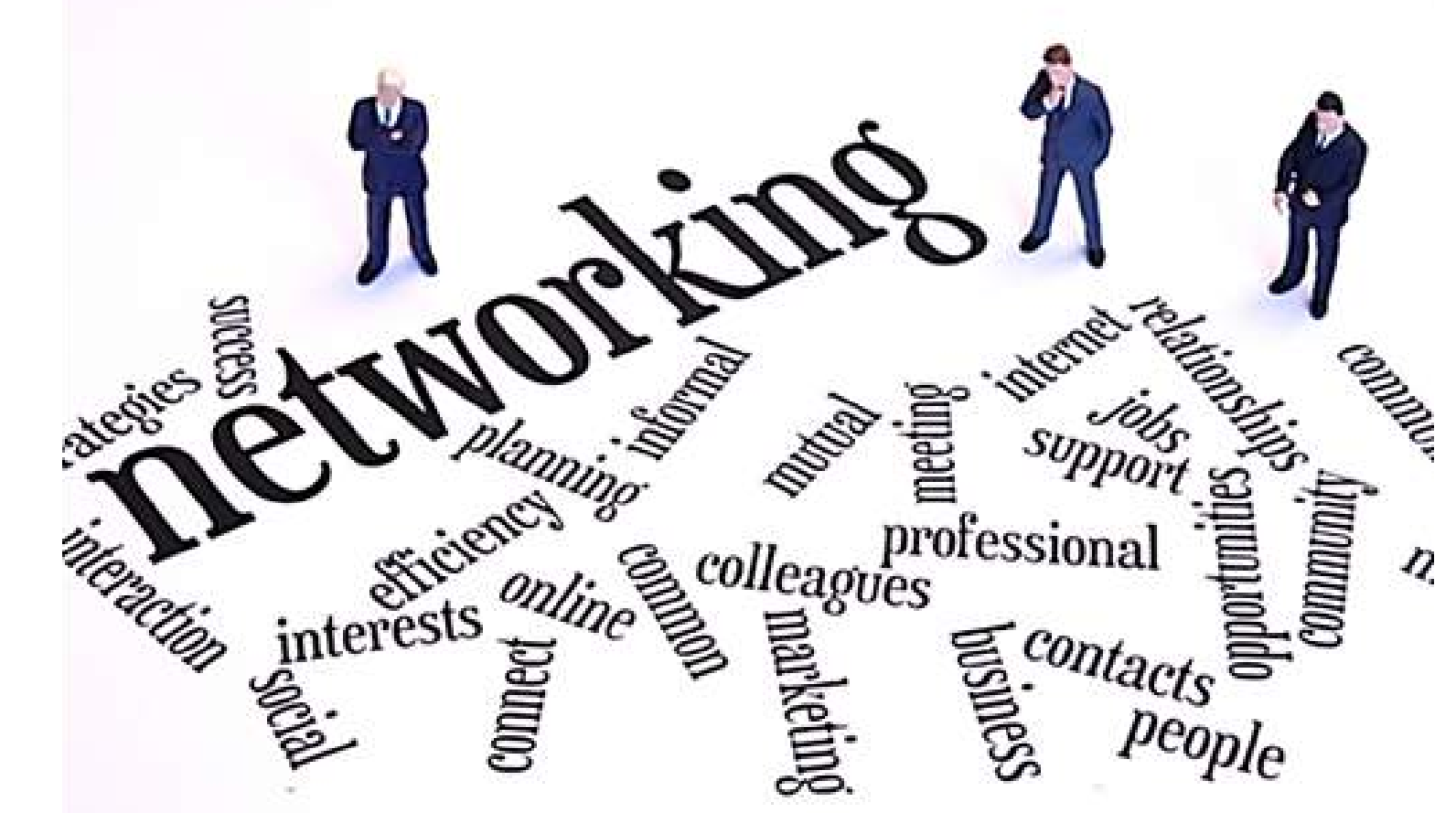

\section{REFERÊNCIAS}

GAMA, Z. A produção científica brasileira está retrocedendo? Justificando, São Paulo, fevereiro, 2018. Seção Artigos. Disponível em: http://www.justificando.com/ 2018/02/05/producaocientifica-brasileira-esta-retrocedendo/. Acesso em: 29 ago. 2019.

MEADOWS, J. Os periódicos científicos e a transição do meio impresso para o eletrônico. Revista de Biblioteconomia de Brasília, v. 25, n.1, p. 5-14, 2001. Disponível em:

http://www.brapci.inf.br/index.php/article/download/12269. Acesso em: 28 ago. 2019. SILVEIRA, L. da; BENEDET, L.; SANTILLÁN-ALDANA, J. Interpretando a internacionalização dos periódicos científicos brasileiros. Motrivivência, Florianópolis, v. 30, n. 54, p. 90-110, jul. 2018. ISSN 2175-8042. Disponível em: https://periodicos.ufsc.br/index.php/motrivivencia/ article/view/2175-8042.2018 v30n 54p90. Acesso em: 06 set. 2019. DOI: https://doi.org/ 10.5007/2175-8042.2018v30n54p90.

SOUZA, M. Produção científica brasileira: caminhos norteadores para instituições de fomento à pesquisa. Brazilian Journal of Information Studies: research trends, v. 12, n.:1, p. 46-60, 2018 Disponível em: http://www2.marilia.unesp.br/revistas/index.php/bjis/article/view/7187/5006 Acesso em: 28 ago. 2019. 